\title{
Isolation of an Aceticlastic Strain of Methanosarcina siciliae from Marine Canyon Sediments and Emendation of the Species Description for Methanosarcina siciliae
}

\author{
M. A. ELBERSON AND K. R. SOWERS* \\ Center of Marine Biotechnology, University of Maryland Biotechnology Institute, \\ Baltimore, Maryland 21202
}

\begin{abstract}
A newly described strain of the genus Methanosarcina was isolated from submarine canyon sediments and is shown by comparative sequence analyses of $16 \mathrm{~S}$ ribosomal DNA and the gene encoding methyl coenzyme $M$ reductase, mcrI, to be a strain of Methanosarcina siciliae. Morphological and physiological characteristics are described. In contrast to the two previously described strains that grow exclusively on methanol, methylamines, and dimethylsulfide, $M$. siciliae $\mathrm{C} 2 \mathrm{~J}$ is also capable of growth on and methanogenesis from acetate. We propose that the species description for $M$. siciliae be amended to include aceticlastic strains.
\end{abstract}

Methanogenic biodegradation is a predominant process in anaerobic marine sediments that are subject to high organic loading, such as the elevated portions of marshes, nearshore sediments, and submarine canyons $(5,8,9,12,13)$. In these environments anaerobic consortia of fermentative bacteria, acetogenic bacteria, and methanogenic archaea degrade polymers and monomers in a synergistic process that yields methane and carbon dioxide as the terminal products (21). Aceticlastic methanogens, such as Methanosarcina spp., have a pivotal role in marine anaerobic consortia since up to $70 \%$ of the methane produced from polymer degradation in sediments is derived from the methyl moiety of acetate $(3,13)$. However, only two aceticlastic methanogens, Methanosarcina acetivorans and Methanosarcina frisia (= Methanosarcina mazei), have been isolated from the marine environment $(2,7,14)$. Methanosarcina siciliae was also isolated from the marine environment, but previously described strains do not utilize acetate for growth $(10,11)$. In this report we describe an aceticlastic methanogenic archaeon designated strain $\mathrm{C} 2 \mathrm{~J}$ that is phylogenetically similar to strains of $M$. siciliae. This strain has physiological characteristics that distinguish it from previously described strains, including the ability to utilize acetate for growth and methanogenesis.

Acetate-utilizing marine methanogenic archaea were enriched from a sediment core retrieved from the Sumner Branch of Scripps Canyon near La Jolla, Calif., at a depth of $19.8 \mathrm{~m}$ below the surface of the water. The sediments consisted of an interwoven mat of sand and partially degraded algae and sea grass. The sediment was black and had a strong sulfide odor. In addition, bubbles were observed rising from sediments when they were disturbed. Contents of the core were pooled under $\mathrm{N}_{2}$. Sediment $(10 \%, \mathrm{vol} / \mathrm{vol})$ was transferred to sterile marine mineral medium that was prepared anaerobically under an $\mathrm{N}_{2}-\mathrm{CO}_{2}$ (4:1) atmosphere as described previously (14). Sodium acetate was included as the only catabolic substrate at a final concentration of $0.1 \mathrm{M}$. In the initial culture, there was a 6-day lag before methane production was observed, which then subsided after 55 days. In all subsequent transfers there was no lag in growth, and methane production subsided within

\footnotetext{
* Corresponding author. Mailing address: Center of Marine Biotechnology, University of Maryland Biotechnology Institute, Columbus Center, Suite 236, 701 E. Pratt Street, Baltimore, MD 21202. Phone: (410) 234-8878. Fax: (410) 234-8899. E-mail: Sowers@umbi.umd.edu.
}

20 days. The predominant cells in enrichment medium were irregularly shaped cocci that occurred singly or in pairs. After four sequential transfers in enrichment medium, serial dilutions of the culture were transferred to agar-solidified medium in roll tubes (14). Several colonies of irregular cocci were isolated, and one colony, designated strain $\mathrm{C} 2 \mathrm{~J}$, was selected for further study.

Colonies were characterized on solidified plating medium as described previously (15). Strain C2J grew as circular, convex, pale yellow colonies that averaged $0.5 \mathrm{~mm}$ and $2 \mathrm{~mm}$ in diameter after 21 days of incubation on medium that contained the catabolic substrates acetate and trimethylamine, respectively. During exponential growth in liquid culture cells were irregularly shaped cocci, $3.4 \pm 0.5 \mu \mathrm{m}$ in diameter, and occurred singly or in pairs (Fig. 1). Motility was not observed. As cultures approached stationary growth, cells formed multicellular aggregates similar to those reported for M. acetivorans (14). Single cells and aggregates were lysed with $0.005 \%$ sodium dodecyl sulfate, which is a characteristic of protein S-layer cell walls reported for Methanosarcina spp. grown in marine media (15).

The $16 \mathrm{~S}$ rRNA- and methyl coenzyme $\mathrm{M}$ reductase $(\mathrm{mcr} \mathrm{I})-$ encoding sequences of strain $\mathrm{C} 2 \mathrm{~J}$ were determined for phylogenetic analysis $(17,19)$. Cells harvested from a $100-\mathrm{ml}$ culture were lysed with $1 \%$ (wt/vol) sodium dodecyl sulfate, and chromosomal DNA was isolated by ethanol precipitation (15). The gene encoding 16S rRNA was amplified by PCR with archaeon-specific forward deoxyoligonucleotide primer $0025 \mathrm{e}$ and universal reverse deoxyoligonucleotide primer 1525 (1). Reaction mixtures contained the following components in a final volume of $20 \mu \mathrm{l}$ in a $200-\mu$ l dome top reaction tube: $1 \times$ PCR buffer (Perkin-Elmer), $200 \mu \mathrm{mol}$ of each deoxyribonucleoside triphosphate, $15 \mathrm{mM} \mathrm{MgCl}, 0.025 \%$ (vol/vol) formamide, $20 \mathrm{pmol}$ of each primer, $1 \mu \mathrm{g}$ of chromosomal DNA, and $0.25 \mathrm{U}$ of AmpliTaq (Perkin-Elmer). PCR were controlled with a Peltier thermocycler (model PTC 200; MJ Research) programmed as follows: $95^{\circ} \mathrm{C}$ for $15 \mathrm{~s}$, followed by 30 cycles consisting of $94^{\circ} \mathrm{C}$ for $15 \mathrm{~s}, 55^{\circ} \mathrm{C}$ for $30 \mathrm{~s}$, and then $72^{\circ} \mathrm{C}$ for 5 min. The gene encoding $m c r$ I was amplified by PCR as described previously (17). Plasmid libraries were generated by directly ligating PCR fragments into plasmid pCRII (Invitrogen) according to the manufacturer's recommendations. The plasmid libraries were screened for clones containing $16 \mathrm{~S}$ ribosomal DNA (rDNA) or $m c r$ I inserts by direct PCR of colonies. Briefly, a colony was transferred to the PCR mixture 


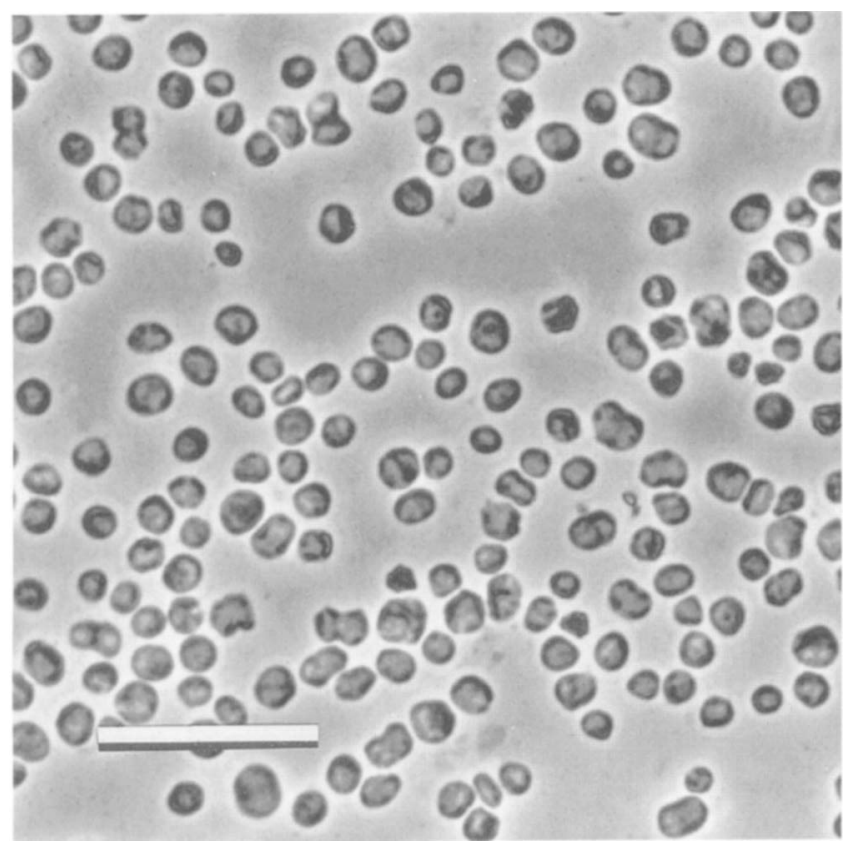

FIG. 1. Phase-contrast micrograph of strain $\mathrm{C} 2 \mathrm{~J}$ grown in trimethylamine. The image was made by using an Olympus Vanox model AHB-T microscope at a magnification of $\times 1,000$. Bar $=20 \mu \mathrm{m}$.

with a sterile toothpick. After the cells lysed during the initial heating cycle, the plasmid insert was amplified by using the primers and thermocycling conditions described above. For sequencing, plasmid DNAs from selected clones were purified with a Qiagen plasmid minikit and were amplified with an $\mathrm{ABI}$ Prism dye terminator cycle sequencing reaction kit (PerkinElmer) according to the manufacturer's recommendations. Both strands of $16 \mathrm{~S}$ rDNA and $m c r I$ were sequenced by using flanking and nested primers for $16 \mathrm{~S}$ rDNA and flanking primers only for $m c r I$. The flanking primers included T7 and SP6, and the nested primers were universal for Escherichia coli $16 \mathrm{~S}$ rRNA positions 519-536, 536-519, 907-926, 926-907, and 14061392 (6). Each reaction mixture was loaded onto an ABI model 373 automated sequencer, and the sequence was analyzed with ABI Prism, version 2.1.1.

The sequences were aligned with representative $16 \mathrm{~S}$ rDNA and $m c r$ sequences in the GenBank database by using PILEUP, version 8 (Genetics Computer Group, Madison, Wis.). Based on a comparison of a 1,350-bp segment of rDNAs, strain $\mathrm{C} 2 \mathrm{~J}$ is phylogenetically related to $M$. siciliae and $M$. acetivorans, with similarities of 99.8 and $99.0 \%$, respectively. Evolutionary distances expressed as estimated numbers of changes per 100 nucleotides were calculated from the percentages of similarity by using the correction of Jukes and Cantor (4). A dendrogram based on the unweighted pair group method with arithmetic averages indicates that strain $\mathrm{C} 2 \mathrm{~J}$ is phylogenetically most closely related to $M$. siciliae (Fig. 2). Since 16S rDNA sequences do not measure phylogenetic distances sufficient to define a species, the phylogeny of the isolate was confirmed by comparative sequence analysis of a 490-bp segment of $\mathrm{mcrI}$, which measures smaller evolutionary distances (17). The isolate had 98.4 and $100 \%$ mcrI sequence similarity with $M$. acetivorans and $M$. siciliae, respectively, indicating that strain $\mathrm{C} 2 \mathrm{~J}$ is an $M$. siciliae strain.

Several morphological and physiological characteristics distinguish this strain from the previously described $M$. siciliae strains, T4/M (= OCM $156=$ DSM 3028) and HI350 (= OCM $210=$ DSM 6564). Single-cell forms of C2J grown in medium containing trimethylamine are larger (diameter, $3.4 \pm 0.5 \mu \mathrm{m}$ ) than strain T4/M cells (diameter, $2.5 \pm 0.2 \mu \mathrm{m}$ ) grown in the same medium and larger than the strain HI350 cells (diameter, 1.5 to $3.0 \mu \mathrm{m}$ ) described previously (11). Under similar growth conditions, strain $\mathrm{C} 2 \mathrm{~J}$ forms aggregates after achieving stationary growth, but strains T4/M and HI350 form aggregates during early exponential growth (10). In addition, strain $\mathrm{C} 2 \mathrm{~J}$ forms large multicellular aggregates up to $1 \mathrm{~mm}$ in diameter compared with strain $\mathrm{T} 4 / \mathrm{M}$, which forms smaller aggregates averaging $0.1 \mathrm{~mm}$ in diameter under the same growth conditions (data not shown).

The physiological characteristics of strain $\mathrm{C} 2 \mathrm{~J}$ were determined by measuring the increase in $A_{550}$ (18-mm path length) with a Spectronic 21 spectrophotometer (Bausch and Lomb). The media used for physiological characterization contained the following constituents (per liter of demineralized water): $\mathrm{NaCl}, 23.38 \mathrm{~g} ; \mathrm{Na}_{2} \mathrm{CO}_{3}, 3.0 \mathrm{~g} ; \mathrm{MgSO}_{4} \cdot 7 \mathrm{H}_{2} \mathrm{O}, 12.6 \mathrm{~g} ; \mathrm{KCl}, 0.76 \mathrm{~g}$; $\mathrm{Na}_{2} \mathrm{HPO}_{4}, 0.6 \mathrm{~g} ; \mathrm{NH}_{4} \mathrm{Cl}, 0.5 \mathrm{~g}$; cysteine hydrochloride $\cdot \mathrm{H}_{2} \mathrm{O}$, $0.25 \mathrm{~g} ; \mathrm{Na}_{2} \mathrm{~S} \cdot 9 \mathrm{H}_{2} \mathrm{O}, 0.25 \mathrm{~g} ; \mathrm{CaCl}_{2} \cdot 2 \mathrm{H}_{2} \mathrm{O}, 0.14 \mathrm{~g}$; and resazurin, $0.001 \mathrm{~g}$. In addition, $1 \%$ ( $\mathrm{vol} / \mathrm{vol}$ ) trace element solution was added (20). The final $\mathrm{pH}$ of the medium was adjusted to 6.8 unless indicated otherwise. Media were dispensed into anaerobe tubes ( 18 by $150 \mathrm{~mm}$; Bellco Glass, Inc.), which were sealed under $\mathrm{N}_{2}-\mathrm{CO}_{2}(4: 1)$ with a butyl rubber septum secured with an aluminum crimp seal. When we tested for hydrogen utilization, the tubes were purged with $\mathrm{H}_{2}-\mathrm{CO}_{2}$ (4:1) and pressurized to $70 \mathrm{kPa}$ after inoculation. Media were sterilized at $121^{\circ} \mathrm{C}$ for $20 \mathrm{~min}$. After autoclaving, methanol was added as the catabolic substrate to a final concentration of $0.1 \mathrm{M}$ unless indicated otherwise.

Strain $\mathrm{C} 2 \mathrm{~J}$ is mesophilic, and the maximum rate of growth occurs at $35^{\circ} \mathrm{C}$ (Fig. 3A). This optimal temperature for growth is approximately $5^{\circ} \mathrm{C}$ below that reported for $M$. siciliae $\mathrm{T} 4 / \mathrm{M}$ and HI350 (11). In addition, growth of strain C2J was observed at $20^{\circ} \mathrm{C}$, which is $5^{\circ} \mathrm{C}$ below the lowest growth temperature reported for the other strains. No growth was observed at $45^{\circ} \mathrm{C}$.

The optimal $\mathrm{pH}$ for growth was determined in medium prepared with organic buffers substituted for carbonate as described previously (14) (Fig. 3B). Strain C2J exhibited the maximum rate of growth at $\mathrm{pH} 6.0$ to 7.0 , a range which is similar to the optimal range reported for $M$. siciliae $\mathrm{T} 4 / \mathrm{M}$ and HI350 (11).

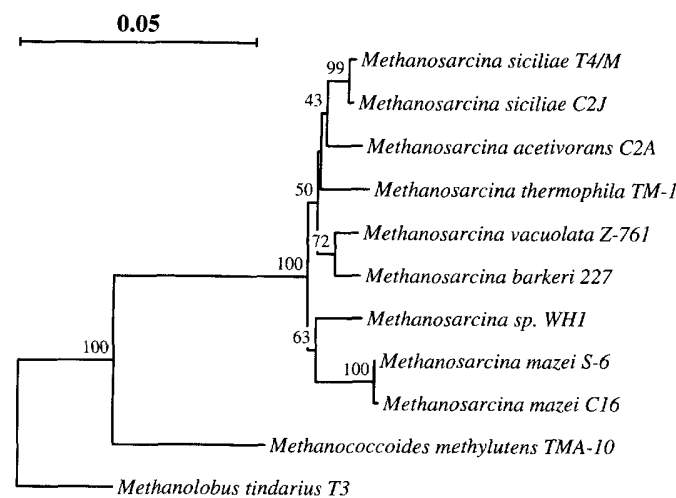

FIG. 2. Comparative sequence analyses of $16 \mathrm{~S}$ rDNAs from $M$. siciliae $\mathrm{C} 2 \mathrm{~J}$ and representative strains from GenBank. The dendrogram was constructed from evolutionary distance matrices with TREECON software by using parameters indicated in the text (18). The significance of each branch is indicated by a bootstrap value calculated for 100 subsets. Bar $=0.05$ substitution/site. 

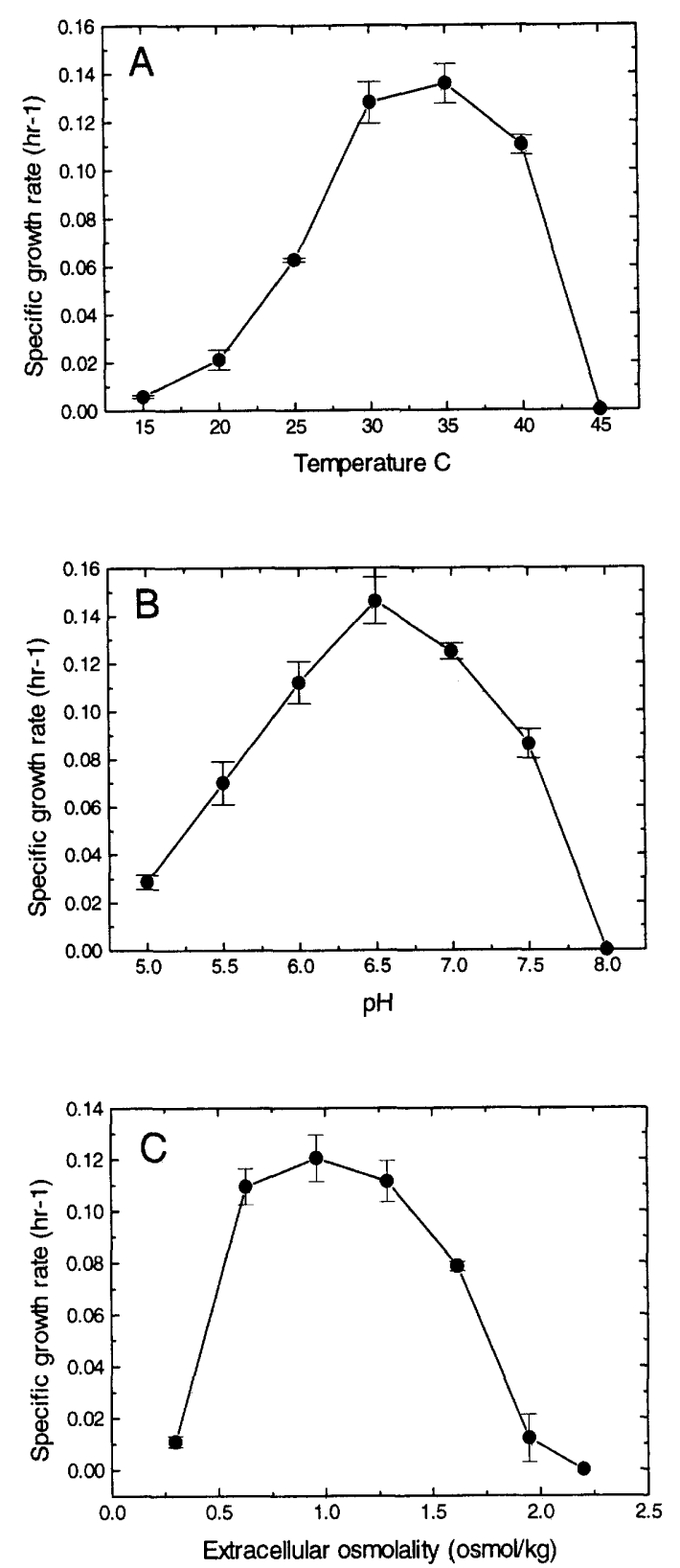

FIG. 3. Effect of temperature (A), $\mathrm{pH}(\mathrm{B})$, and extracellular solute concentration $(\mathrm{C})$ on the growth rate of strain $\mathrm{C} 2 \mathrm{~J}$ on methanol. Values are means \pm 1 standard deviation for three to six replicate cultures.

The range of medium osmolalities that support maximum rates of growth were determined in medium that contained a range of $\mathrm{NaCl}$ concentrations as described previously (16) (Fig. $3 \mathrm{C})$. Strain $\mathrm{C} 2 \mathrm{~J}$ has a maximum rate of growth at 0.6 to 1.3 osmol $/ \mathrm{kg}$ (corresponding to addition of 0.2 to $0.6 \mathrm{M} \mathrm{NaCl}$ ). Like other strains of $M$. siciliae, strain C2J grows poorly at 0.3 osmol/kg (no addition of $\mathrm{NaCl}$ ) (11). Therefore, this newly described strain, like previously described strains of $M$. siciliae, is slightly halophilic, which distinguishes it from other species of the genus Methanosarcina, which are halotolerant $(7,16)$.

After at least three sequential transfers in medium containing either methanol, trimethylamine $(0.1 \mathrm{M})$, or dimethylsulfide $(4.4 \mathrm{mM})$ as a catabolic substrate, strain C2J exhibited specific growth rates of $0.14 \pm 0.008,0.09 \pm 0.002$, and $0.03 \pm$
$0.005 \mathrm{~h}^{-1}$, respectively, which are similar to growth rates reported for strain HI350 (11). However, unlike previously reported strains of $M$. siciliae, medium containing sodium acetate $(0.1 \mathrm{M})$ as a catabolic substrate supported growth of strain $\mathrm{C} 2 \mathrm{~J}$ with a specific growth rate of $0.009 \pm 0.001 \mathrm{~h}^{-1}$ after three sequential transfers (11). Acetate-grown strain C2J did not grow or produce methane when it was transferred to medium that contained sodium formate $(0.1 \mathrm{M})$ or $\mathrm{H}_{2}-\mathrm{CO}_{2}$ as the sole substrate. Trypticase, yeast extract, Casamino Acids, and vitamins (each at a concentration of $0.1 \%$, wt/vol) were not required for growth in minimal medium and did not significantly stimulate growth.

Our results show that strain $\mathrm{C} 2 \mathrm{~J}$ is a strain of $M$. siciliae based on comparative sequence analysis of $16 \mathrm{~S}$ rDNA and $m c r I$. Characteristics that distinguish this strain from the previously described strains, T4/M and HI350, include larger cell size, formation of larger aggregates during stationary growth, and lower minimal and optimal growth temperatures. However, the most distinguishing trait is the ability of strain $\mathrm{C} 2 \mathrm{~J}$ to use acetate for growth and methanogenesis. The current description of $M$. siciliae as a nonaceticlastic, obligate methylotroph is hereby emended to include aceticlastic strains. The description is also emended to include a cell size range of 1.5 to $4 \mu \mathrm{m}$ and a temperature range of 35 to $40^{\circ} \mathrm{C}$ for optimal growth. Strain C2J has been deposited in the Oregon Collection of Methanogens as OCM 653.

Nucleotide sequence accession number. The $16 \mathrm{~S}$ rDNA nucleotide sequence of strain $\mathrm{C} 2 \mathrm{~J}$ has been deposited in the GenBank/EMBL Data Bank under accession no. U89773.

We thank E. Apolinario for technical assistance and D. R. Boone for helpful discussions.

This work was supported by grant DE-FG02-93ER20106 from the U.S. Department of Energy, Division of Energy Biosciences.

\section{REFERENCES}

1. Achenbach, L., and C. Woese. $1995.16 \mathrm{~S}$ and 23S rRNA-like primers, p. 521523. In F. T. Robb, A. R. Place, K. R. Sowers, H. J. Schreier, S. DasSharma, and E. M. Fleischmann (ed.), Archaea: a laboratory manual-methanogens. Cold Spring Harbor Laboratory Press, Plainview, N.Y.

2. Blotevogel, K.-H., and U. Fischer. 1989. Transfer of Methanococcus frisius to the genus Methanosarcina as Methanosarcina frisia comb. nov. Int. J. Syst. Bacteriol. 39:91-92.

3. Christensen, D., and T. H. Blackburn. 1982. Turnover of ${ }^{14} \mathrm{C}$-labelled acetate in marine sediments. Mar. Biol. 71:113-119.

4. Jukes, T. H., and C. R. Cantor. 1969. Evolution of protein molecules, p. 21-132. In H. N. Munro (ed.), Mammalian protein metabolism. Academic Press, New York, N.Y.

5. King, G. M., and W. J. Wiebe. 1980. Tracer analysis of methanogenesis in salt marsh soils. Appl. Environ. Microbiol. 39:877-881.

6. Lane, D. J., B. Pace, G. J. Olsen, D. A. Stahl, M. L. Sogin, and N. R. Pace. 1985. Rapid determination of $16 \mathrm{~S}$ ribosomal sequences for phylogenetic analyses. Proc. Natl. Acad. Sci. USA 82:6955-6959.

7. Maestrojuán, G. M., J. E. Boone, R. A. Mah, J. A. G. F. Menaia, M. S. Sachs, and D. R. Boone. 1992. Taxonomy and halotolerance of mesophilic Methanosarcina strains, assignment of strains to species, and synonymy of Methanosarcina mazei and Methanosarcina frisia. Int. J. Syst. Bacteriol, 42:561567.

8. Martens, C. S., and R. A. Berner. 1974. Methane production in the interstitial waters of sulfate-depleted marine sediments. Science 185:1167-1169.

9. Mountfort, D. O., and R. A. Asher. 1981. Role of sulfate reduction versus methanogenesis in terminal carbon flow in polluted intertidal sediment of Waimea Inlet, Nelson, New Zealand. Appl. Environ. Microbiol. 42:252-258.

10. Ni, S., C. R. Woese, H. C. Aldrich, and D. R. Boone. 1994. Transfer of Methanosarcina siciliae to the genus Methanosarcina, naming it Methanosarcina siciliae, and emendation of the genus Methanosarcina. Int. J. Syst. Bacteriol. 44:357-359.

11. Ni, S., and D. R. Boone. 1991. Isolation and characterization of a dimethyl sulfide-degrading methanogen, Methanolobus siciliae HI350, from an oil well, characterization of $M$. siciliae $\mathrm{T} 4 / \mathrm{M}^{\mathrm{T}}$, and emendation of $M$. siciliae. Int. J. Syst. Bacteriol. 41:410-416.

12. Oremland, R. S., L. M. Marsh, and S. Polcin. 1982. Methane production and simultaneous sulphate reduction in anoxic, salt marsh sediments. Nature 296:143-145. 
13. Sansone, F. J., and C. S. Martens. 1981. Methane production from acetate and associated methane fluxes from anoxic coastal sediments. Science 211: 707-709.

14. Sowers, K. R., S. F. Baron, and J. G. Ferry. 1984. Methanosarcina acetivorans sp. nov., an acetotrophic methane-producing bacterium isolated from marine sediments. Appl. Environ. Microbiol. 47:971-978.

15. Sowers, K. R., J. E. Boone, and R. P. Gunsalus. 1993. Disaggregation of Methanosarcina spp. and growth as single cells at elevated osmolarity. Appl. Environ. Microbiol. 59:3832-3839.

16. Sowers, K. R., and R. P. Gunsalus. 1995. Halotolerance in Methanosarcina spp.: role of Ne-acetyl- $\beta$-lysine, $\alpha$-glutamate, glycine betaine, and $\mathrm{K}^{+}$as compatible solutes for osmotic adaptation. Appl. Environ. Microbiol. 61: $4382-4.388$.
17. Springer, E., M. S. Sachs, C. R. Woese, and D. R. Boone. 1995. Partial gene sequences for the A subunit of methyl-coenzyme $\mathbf{M}$ reductase $(\mathrm{mcr} \mathrm{I})$ as a phylogenetic tool for the family Methanosarcinaceae. Int. J. Syst. Bacteriol. 45:554-559.

18. Van de Peer, Y., and R. De Wachter. 1994. TREECON for Windows: a software package for the construction and drawing of evolutionary trees for the Microsoft Windows environment. Comput. Applic. Biosci. 10:569-570.

19. Woese, C. R. 1987. Bacterial evolution. Microbiol. Rev. 51:221-271.

20. Wolin, E. A., M. J. Wolin, and R. S. Wolfe. 1963. Formation of methane by bacterial extracts. J. Biol. Chem. 238:2882-2886.

21. Zinder, S. H. 1993. Physiological ecology of methanogens, p. 128-206. In J. G. Ferry (ed.), Methanogenesis. Chapman and Hall, New York, N.Y. 